\title{
Behavioral effects of endogenous or exogenous estradiol and progesterone on cocaine sensitization in female rats
}

\author{
M.F. Souza ${ }^{1}$, N.S. Couto-Pereira ${ }^{2}$, L. Freese ${ }^{1}$, P.A. Costa $^{1}$, G. Caletti ${ }^{1}$, K.M. Bisognin ${ }^{1}$, M.S. Nin ${ }^{1,3}$, \\ R. Gomez ${ }^{4}$ and H.M.T. Barros ${ }^{1}$ \\ ${ }^{1}$ Laboratório de Neurociência Comportamental, Universidade Federal de Ciências da Saúde de Porto Alegre, \\ Porto Alegre, RS, Brasil \\ ${ }^{2}$ Departamento de Bioquímica, Instituto de Ciências Básicas da Saúde, Universidade Federal do Rio Grande do Sul, \\ Porto Alegre, RS, Brasil \\ ${ }^{3}$ Curso de Farmácia, Centro Metodista do Sul, Instituto Porto Alegre, Porto Alegre, RS, Brasil \\ ${ }^{4}$ Departamento de Farmacologia, Instituto de Ciências Básicas da Saúde, Universidade Federal do Rio Grande do Sul, \\ Porto Alegre, RS, Brasil
}

\begin{abstract}
Cocaine sensitization is a marker for some facets of addiction, is greater in female rats, and may be influenced by their sex hormones. We compared the modulatory effects of endogenous or exogenous estradiol and progesterone on cocaine-induced behavioral sensitization in 106 female rats. Ovariectomized female rats received progesterone $(0.5 \mathrm{mg} / \mathrm{mL})$, estradiol $(0.05 \mathrm{mg} / \mathrm{mL})$, progesterone plus estradiol, or the oil vehicle. Sham-operated control females received oil. Control and acute subgroups received injections of saline, while the repeated group received cocaine $(15 \mathrm{mg} / \mathrm{kg}$, ip) for 8 days. After 10 days, the acute and repeated groups received a challenge dose of cocaine, after which locomotion and stereotypy were monitored. The estrous cycle phase was evaluated and blood was collected to verify hormone levels. Repeated cocaine treatment induced overall behavioral sensitization in female rats, with increased locomotion and stereotypies. In detailed analysis, ovariectomized rats showed no locomotor sensitization; however, the sensitization of stereotypies was maintained. Only females with endogenous estradiol and progesterone demonstrated increased locomotor activity after cocaine challenge. Estradiol replacement enhanced stereotyped behaviors after repeated cocaine administration. Cocaine sensitization of stereotyped behaviors in female rats was reduced after progesterone replacement, either alone or concomitant with estradiol. The behavioral responses (locomotion and stereotypy) to cocaine were affected differently, depending on whether the female hormones were of an endogenous or exogenous origin. Therefore, hormonal cycling appears to be an important factor in the sensitization of females. Although estradiol increases the risk of cocaine sensitization, progesterone warrants further study as a pharmacological treatment in the prevention of psychostimulant abuse.
\end{abstract}

Key words: Cocaine; Locomotor activity; Female rats; Estradiol; Progesterone; Stereotypic activity

\section{Introduction}

Behavioral sensitization occurs after repeated psychostimulant use and is well described for drugs such as cocaine. This phenomenon is characterized by enhanced stereotypy or motor-stimulant response, after a delay of days or weeks, following repeated intermittent administration of psychostimulants. Behavioral sensitization is thought to underlie some facets of cocaine addiction, including craving and relapse (1).

The prevalence of cocaine use and abuse has been increasing rapidly among women in recent years. In fact, women are more likely to use cocaine at an earlier age and with a higher frequency than men (2). Moreover, women tend to take less time to become addicted, use it in larger amounts, and show more craving signals than men (3). Similarly, in experimental animals, the hormonal differences between males and females appear to influence both the use of cocaine and its behavioral effects, with females showing more intense acute behavioral effects than males (4). Female rats have also been found to have more intense responses to the repeated administration of cocaine in studies involving sensitization, conditioned place preference, self-administration, and dose escalation (5). 
Hormonal fluctuations play an important role in women's responses to drugs, suggesting that sex steroids modulate the subjective actions of cocaine (6). Indeed, the reinforcing effects of drug abuse are greater during the follicular phase in women, and craving sensations are stronger when estrogen and progesterone levels are high (7). In female rats, the behavioral effects of cocaine vary with the estrous cycle phase (8). Interestingly, the behavioral responses to cocaine are enhanced in the proestrous and estrous phases in female rats, when estrogen and progesterone levels are high (9-11). Ovariectomy abolishes the behavioral differences in response to cocaine administration between male and female rats and also delays behavioral sensitization and self-administration in female rats (12), suggesting that hormonal fluctuations have a positive effect on the reinforcing properties of cocaine.

Despite the relevance of the hormonal condition on psychostimulant intake, the influence of the concomitant administration of progesterone and estrogen in females receiving repeated cocaine exposures is poorly understood. It is already known in rodents that estrogen increases sensitization $(13,14)$, cocaine self-administration $(15,16)$, and relapses during the reinstatement phase (17). However, progesterone appears to attenuate the effects of cocaine, acting as a protective factor. Exogenous treatment with progesterone reverses the effects of estrogen relative to the acquisition of self-administration of cocaine, attenuation of the motor response, and inhibition of the place preference for cocaine (18). In addition, cocaine-induced hyperactivity and self-administration are less intense during stages of the estrous cycle in which progesterone levels are high $(10,16)$. A significant increase in responses also occurs during the reinstatement of cocaine use in rats during estrous phases relative to non-estrous phases, and this effect is selectively attenuated by progesterone (19). Despite several studies showing the attenuation of cocaine effects by progesterone, other authors observed that progesterone might not have any influence (20) or may even potentiate psychostimulant effects (21).

Overall, studies investigating the effects of physiological variations in hormonal cycles or hormone replacement therapy on cocaine-induced behavioral sensitization in females are scarce. It seems reasonable to expect that estrogen increases and progesterone decreases the effects of cocaine, and that progesterone attenuates the effects of estrogen on cocaine when both hormones are on board. Thus, the aim of this study was to compare the modulatory effects of endogenous or exogenous estradiol and progesterone on cocaine-induced behavioral sensitization in female rats.

\section{Material and Methods}

\section{Animals}

Adult female Wistar rats (2 months old, 200-250 g; $\mathrm{n}=106$; $6-7$ animals for ovariectomized groups and 12 for sham-operated groups) were obtained from the Animal Facility of Universidade Federal de Ciências da Saúde de Porto Alegre (UFCSPA). The animals were housed in groups of five in polypropylene cages $(33 \times 17 \times 40 \mathrm{~cm})$. Food and water were available ad libitum, and the animals were maintained in a temperature-controlled room $\left(23 \pm 2^{\circ} \mathrm{C}\right)$ under a $12: 12$-h light-dark cycle (lights on from 7:00 am to 7:00 pm). All in vivo experiments followed the guidelines of the International Council for Laboratory Animal Science and were approved by the Ethics Committee for Research of UFCSPA (\#1034/10). All efforts were made to minimize animal suffering and to use only the number of animals necessary to produce reliable scientific data.

\section{Drugs}

Cocaine hydrochloride (Merck, Germany) at $15 \mathrm{mg} /$ $\mathrm{mL}$ was dissolved in saline. Progesterone (Sigma-Aldrich, Brazil) and estradiol benzoate (Sigma-Aldrich) were dissolved in an oil vehicle at concentrations of 0.5 and $0.05 \mathrm{mg} / \mathrm{mL}$, respectively.

\section{Procedures}

Bilateral ovariectomies were performed in 70 rats under intraperitoneal (ip) anesthesia with $10 \mathrm{mg} / \mathrm{kg}$ xylazine and $75 \mathrm{mg} / \mathrm{kg}$ ketamine hydrochloride. Sham surgeries were performed in 36 rats (SHAM). Ovariectomized rats were randomly assigned to progesterone (PRO), estradiol (EST), progesterone plus estradiol (PRO +EST), or control ovariectomized (OVX) groups. The SHAM and OVX groups received the oil vehicle at $1 \mathrm{~mL} / \mathrm{kg}$. Administration of sex hormones $(0.5 \mathrm{mg} / \mathrm{kg}$ progesterone and $0.05 \mathrm{mg} / \mathrm{kg}$ estrogen) or vehicle $(1 \mathrm{~mL} / \mathrm{kg})$ began 10 days after ovariectomy or sham surgery (17) and was carried out by subcutaneous injection (Figure 1).

One day after the beginning of hormonal treatment, the rats were randomly assigned to receive either $1 \mathrm{~mL} / \mathrm{kg}$ saline ip [control (CTR) or acute (ACT) groups] or $15 \mathrm{mg} /$ $\mathrm{kg}$ cocaine ip [repeated (RPT) group], once a day, for 8 consecutive days (sensitization phase). The rats were then submitted to a wash-out administration period of 10 days, after which they received a single challenge dose of either saline ip (CTR group) or $15 \mathrm{mg} / \mathrm{kg}$ cocaine ip (ACT and RPT groups) (22).

\section{Estrous cycle analysis and sex hormone analysis}

The estrous cycle was monitored by examining the cellular characteristics of vaginal smears collected after conducting the behavioral assessments (23). In addition, at the end of the behavioral tests, the animals were killed by decapitation, and trunk blood was collected from the site and centrifuged at $500 \mathrm{~g}$, and the serum was then stored at $-20^{\circ} \mathrm{C}$ for subsequent analysis of the hormone levels. Estradiol (calibrator range $20-3200 \mathrm{pg} / \mathrm{mL}$ ) and progesterone (calibrator range $0.2-40 \mathrm{ng} / \mathrm{mL}$ ) levels were determined by ELISA using commercial reagents (Diagnostics Biochem Canada Inc., Canada, and Symbiosys, Brazil, respectively). 


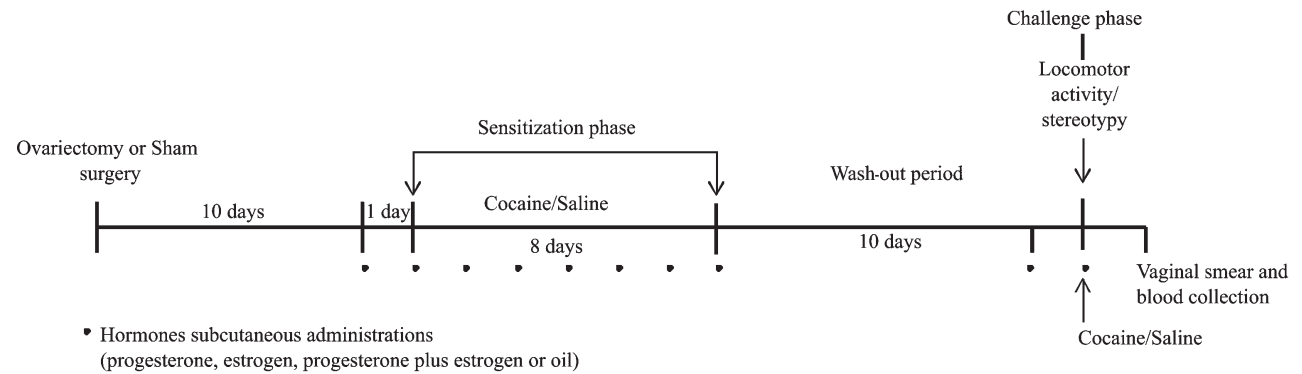

Figure 1. Schematic time-line representation of experimental design.

\section{Behavioral activity}

Rats were placed individually, for $10 \mathrm{~min}$, in a locomotor activity cage $(80 \times 26 \times 22 \mathrm{~cm})$ with three photocells (Alsbarsch, Brazil) to monitor horizontal locomotor activity. This procedure also had the purpose of habituating the rats to the experimental apparatus. After the habituation period, the rats received saline or cocaine and were immediately returned to the locomotor activity cage. Based on the protocol of Scheggi et al. (22), the locomotor activity of rats was monitored for $30 \mathrm{~min}$, and locomotion counts were registered every $10 \mathrm{~min}$.

Each animal was videotaped in the locomotion cage, and its behavior was analyzed during a 30-s time window at 10,20 , and $30 \mathrm{~min}$ after the injection of cocaine or saline. The videotapes were analyzed for behavioral stereotypy by a trained observer blind to the treatment of each animal. The rating for cocaine-induced stereotypic behavior was based on a modification (24) of the Creese and Iversen scale (25) (see Table 1).

\section{Statistical analysis}

One-way ANOVA followed by the Student-NewmanKeuls post hoc comparison was used to determine the statistical significance of the mean values for the progesterone and estradiol levels. One-way ANOVA followed by the Student-Newman-Keuls post hoc comparison was used to determine the statistical significance of the total

Table 1. Daunais and McGinty (24) stereotypy scale.

\begin{tabular}{ll}
\hline Score & \multicolumn{1}{c}{ Behavior } \\
\hline 1 & Asleep, inactive \\
2 & Alert, actively grooming \\
3 & Increased sniffing in one location \\
4 & Intermittent rearing and sniffing \\
5 & Increased locomotion and sniffing \\
6 & Intense sniffing in one location \\
7 & Continuous pivoting and sniffing \\
8 & Continuous rearing and sniffing \\
9 & Maintained rearing and sniffing for $>25 \mathrm{~s}$ \\
10 & Splayed hind limbs \\
\hline
\end{tabular}

scores of locomotion and stereotypy. Two-way repeated measures ANOVA followed by the Student-Newman-Keuls post hoc comparison was used to determine the statistical significance of the locomotion counts and stereotypy scores according to time. Correlation between locomotion counts and stereotypy score was analyzed using the Spearman test. $\mathrm{P}<0.05$ was accepted as the level of significance.

\section{Results}

\section{Estrous cycle and hormonal analysis}

Analysis of the estrous cycle on the challenge day showed that $48 \%$ SHAM rats were in metestrus $(n=16)$, $24 \%$ in diestrus $(n=8), 14 \%$ in proestrus $(n=6)$, and only $14 \%$ in estrus $(n=6)$. Rats in the SHAM and OVX groups had vaginal cellular characteristics corresponding to the specific hormonal treatment, as described by Montes and Luque (26). The analysis of hormone levels in the serum collected on the last experimental day (Table 2) indicated that progesterone levels were higher in the SHAM, PRO, and $\mathrm{PRO}+\mathrm{EST}$ groups than in the OVX rats $\left(\mathrm{F}_{(4,73)}=2.945\right.$; $P=0.026)$. Likewise, estradiol levels were significantly higher in the SHAM, EST, and PRO + EST rats than in the OVX rats $\left(F_{(4,79)}=3.396 ; P=0.013\right)$.

\section{Behavioral observations}

Repeated administration of cocaine during the sensitization protocol showed behavioral consequences in both the locomotor and stereotypy observations in female rats. After a subsequent challenge with cocaine at $15 \mathrm{mg} / \mathrm{kg}$, the total locomotion (mean \pm SE) in RPT animals (427.90 \pm 47.98$)$ was significantly higher than in ACT animals (281.58 \pm 35.22), and both were higher than in the CTR group $\left(50.25 \pm 8.20 ; F_{\text {treat }(2,73)}=29.21 ; P<0.001\right)$. However, behavioral differences varied according to the hormonal condition of the rats, with only the SHAM animals exhibiting locomotion sensitization $\left(F_{\text {treat }(2,16)}=12.82 ; \mathrm{P}<0.001\right)$. Analysis of locomotor activity of females in different hormonal conditions during the $\mathbf{3 0}$ min following administration of saline or cocaine challenge is reported in Figure 2A-E. Locomotion of the SHAM rats (Figure $2 \mathrm{~A}$ ) was the highest, followed by RPT cocaine, then ACT at 10 and 
Table 2. Hormonal concentrations according to sex hormone-treated group on the last experimental day and number of animals according to estrous cycle phase in SHAM rats.

\begin{tabular}{|c|c|c|c|c|c|c|}
\hline & \multicolumn{2}{|c|}{ SHAM } & ovX & $\mathrm{PRO}+\mathrm{EST}$ & PRO & EST \\
\hline \multirow[t]{5}{*}{ Progesterone $(\mathrm{ng} / \mathrm{mL})$} & \multicolumn{2}{|c|}{$26.2 \pm 4.4^{*}$} & $6.15 \pm 1.28$ & $13.22 \pm 2.93^{*}$ & $16.03 \pm 3.38^{*}$ & $5.68 \pm 0.85$ \\
\hline & Metestrus $(12 / 36)$ & $18.7 \pm 5.2$ & & & & \\
\hline & Diestrus $(6 / 36)$ & $38.9 \pm 28.3$ & & & & \\
\hline & Proestrus $(9 / 36)$ & $29.2 \pm 14.4$ & & & & \\
\hline & Estrus $(9 / 36)$ & $30.3 \pm 5.14$ & & & & \\
\hline \multirow[t]{5}{*}{ Estradiol $(\mathrm{pg} / \mathrm{mL})$} & \multicolumn{2}{|c|}{$104.8 \pm 21.2^{*}$} & $42.41 \pm 5.91$ & $75.31 \pm 12.82^{*}$ & $35.45 \pm 7.10$ & $130.61 \pm 24.09^{*}$ \\
\hline & Metestrus $(12 / 36)$ & $135.8 \pm 53.2$ & & & & \\
\hline & Diestrus $(6 / 36)$ & $57.5 \pm 17.7$ & & & & \\
\hline & Proestrus $(9 / 36)$ & $98.6 \pm 29.0$ & & & & \\
\hline & Estrus $(9 / 36)$ & $86.9 \pm 10.9$ & & & & \\
\hline
\end{tabular}

Data are reported as means \pm SE and number of SHAM rats in each estrous cycle phase. SHAM: sham-operated; OVX: ovariectomized; PRO + EST: progesterone + estradiol; PRO: progesterone; EST: estradiol. ${ }^{*} \mathrm{P}<0.05$ compared to OVX (one-way ANOVA followed by the Student-Newman-Keuls test).

20 min after cocaine administration, with both RPT and ACT higher than CTR over time. No significant change was detected in the locomotion of OVX rats treated with ACT or RPT cocaine (Figure 2B). In both groups that received estradiol, i.e., PRO + EST (Figure 2C) and EST (Figure 2E), there were no differences between RPT and ACT cocaine treatment; both increased locomotion equally at $10 \mathrm{~min}$. However, in the group receiving PRO replacement (Figure 2D), only RPT cocaine animals showed higher locomotion than CTR at $10 \mathrm{~min}$ after cocaine administration $\left(F_{\text {group }(14,146)}=5.85 ; P<0.001 ; F_{\text {time }(2,146)}=9.66 ; P<0.001\right.$; $\left.\mathrm{F}_{\text {int }(28,146)}=1.99 ; \mathrm{P}=0.005\right)$.

When the stereotypic behavioral scores were summed, the results (means $\pm \mathrm{SE}$ ) indicated that the RPT cocainetreated rats $(13.89 \pm 0.54)$ exhibited higher stereotypy than the ACT animals (11.03 \pm 0.54$)$, and scores were higher in both RPT and ACT than in CTR rats $(5.36 \pm 0.53$; $\left.F_{\text {treat(2,57) }}=66.59 ; P<0.001\right)$. Cocaine-induced stereotypy also differed according to the hormonal condition of the rats, with less stereotypies after repeated cocaine in OVX, $\mathrm{PRO}$, and $\mathrm{PRO}+\mathrm{EST}$ groups relative to both SHAM and EST animals $\left(F_{\text {cond }(4,57)}=2.75 ; P=0.04\right)$. Analysis of stereotypy during the 30 min following the administration of saline or cocaine challenge treatment revealed significant differences according to the cocaine treatment and hormonal condition $\left(F_{(14,57)}=10.84 ; P<0.001\right)$, as illustrated in Figure $3 \mathrm{~A}-\mathrm{E}$. The results indicated that the SHAM animals (Figure $3 A$ ) treated with cocaine (ACT or RPT) presented a higher stereotypy score than CTR animals over time. The RPT group presented higher stereotypy than the ACT group at 20 min after cocaine challenge. In OVX rats (Figure $3 \mathrm{~B}$ ), ACT cocaine administration enhanced stereotypy at 20 and 30 min after challenge compared with CTR animals. The RPT group presented higher stereotypy behavior than both the CTR and ACT groups at 20 and 30 min after cocaine administration. In contrast, stereotypy of the PRO+EST (Figure 3C) and
PRO rats (Figure 3D) did not differ in the RPT and ACT cocaine-treated animals, but it was higher in both the RPT and ACT groups than in the CTR saline-treated animals. In the EST group (Figure 3E), ACT and RPT cocaine enhanced stereotypy behavior when compared to CTR over time, while RPT cocaine-treated rats presented higher stereotypy than ACT at 10 and 20 min after cocaine challenge.

When the influence of the estrous cycle phase was considered in SHAM female rats, the RPT group had higher total locomotor activity than the ACT group when in estrus $\left(F_{\text {treat(2,25) }}=10.674 ; P<0.001\right.$; Figure $\left.4 A\right)$. However, when the sum of punctuation on the stereotypy scale was considered (Figure 4B), the RPT group presented higher stereotypy than the ACT group when in proestrus $\left(F_{\text {treat }(2,18)}=34.317 ; P=0.009\right)$. The powers of the tests (associated with $F_{\text {treat }}$ ) performed on the locomotion and stereotypy results were 0.977 and 0.975 , respectively.

Comparing locomotion counts with stereotypy scores of repeated cocaine-treated rats, we observed an inverse correlation between these two variables in the SHAMRPT group $(R=-0.62 ; P=0.028 ;$ Figure 5$)$. On the contrary, in the OVX-RPT animals (Figure 5), we observed a direct correlation between locomotion and stereotypy $(R=0.85 ; P=0.002)$.

\section{Discussion}

We have shown here that endogenous or exogenous estradiol and progesterone differentially affect the behavioral responses to cocaine sensitization in female rats. Interestingly, we found that the regular hormonal cycling in intact, sham-operated female rats was the only hormonal condition that showed sensitization of locomotor activity after a later cocaine challenge. However, when stereotypy behaviors were considered as a characteristic of cocaine sensitization, we found that all hormonal 

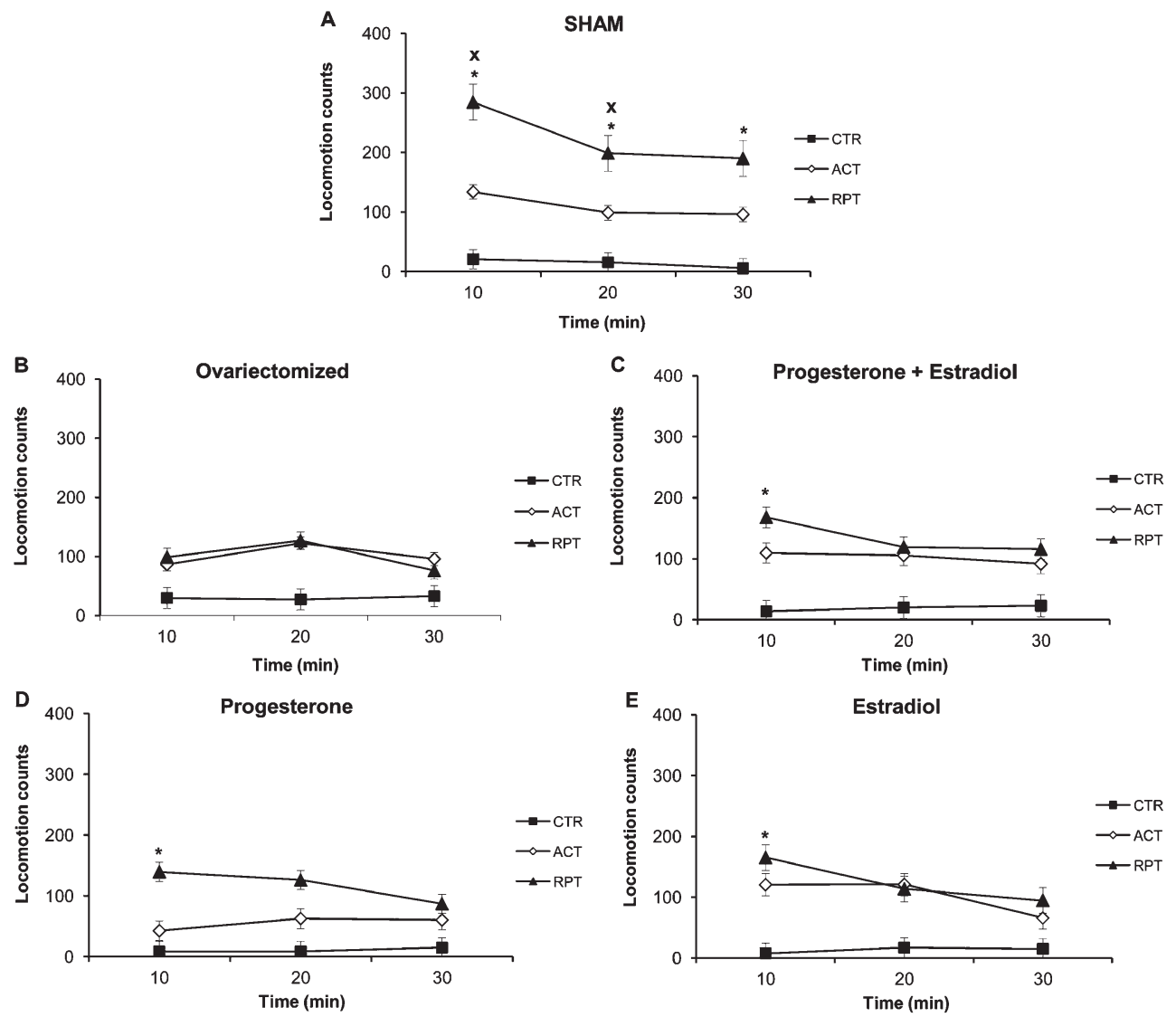

Figure 2. Locomotor activity of female rats over the $30 \mathrm{~min}$ following administration of saline (CTR) or cocaine to acute (ACT) or repeated cocaine exposure (RPT) rats on the challenge treatment day, according to the different hormonal conditions. $A$, Shamoperated (SHAM) female rats. $B$, Ovariectomized female rats. $C$, Ovariectomized female rats treated with progesterone plus estradiol. $D$, Ovariectomized female rats treated with progesterone. $E$, Ovariectomized female rats treated with estradiol. Data are reported as means \pm SE. ${ }^{*} \mathrm{P}<0.05$ compared to CTR; ${ }^{\times} \mathrm{P}<0.05$ compared to ACT (two-way repeated measures ANOVA followed by the StudentNewman-Keuls test).

conditions, except exogenous progesterone administration (combined or not with estradiol), were able to promote sensitization in female rats.

Our results are consistent with previous studies (13), indicating that repeated cocaine treatment induces behavioral sensitization in female rats, demonstrated by both an increase in locomotion and stereotypy behaviors. However, after a cocaine challenge in ovariectomized female rats, we did not observe locomotor sensitization even though stereotypy sensitization remained. It is already known that repeated high doses of cocaine treatment in intact female rats induce a classical dopaminergic syndrome characterized by increased locomotion followed by increased stereotypies and hind limb splaying, thus decreasing the initial hyperlocomotion (27). In fact, hyperlocomotion or stereotypies (27) are not uncommon after psychostimulant administration in animals. Studies have previously shown that administration of low to moderate cocaine doses increases locomotor activity, while higher doses or repeated administration produce stereotypy rather than locomotor activity in rodents $(27,28)$. In our current study, for all hormonal conditions in sensitized female rats, we observed a tendency for an increase in stereotypy in detriment to locomotor activity $30 \mathrm{~min}$ after the cocaine challenge. This behavior pattern is usually observed following very high doses of psychostimulants and/or chronic drug administration in rodents (28). Because of the competition between locomotor activity and stereotypic behaviors, we may infer that locomotion is not the only behavior directly related to the magnitude of the response to the cocaine challenge in the sensitized rats. Thus, our results are evidence of the importance of the concurrent evaluation of both locomotor and stereotypy behaviors in similar studies conducted in the future.

The study of drug effects in females is instructive because the interaction of hormone fluctuations with the physiological effects of the drug can induce behavioral differences to the same drug dose between individuals or 

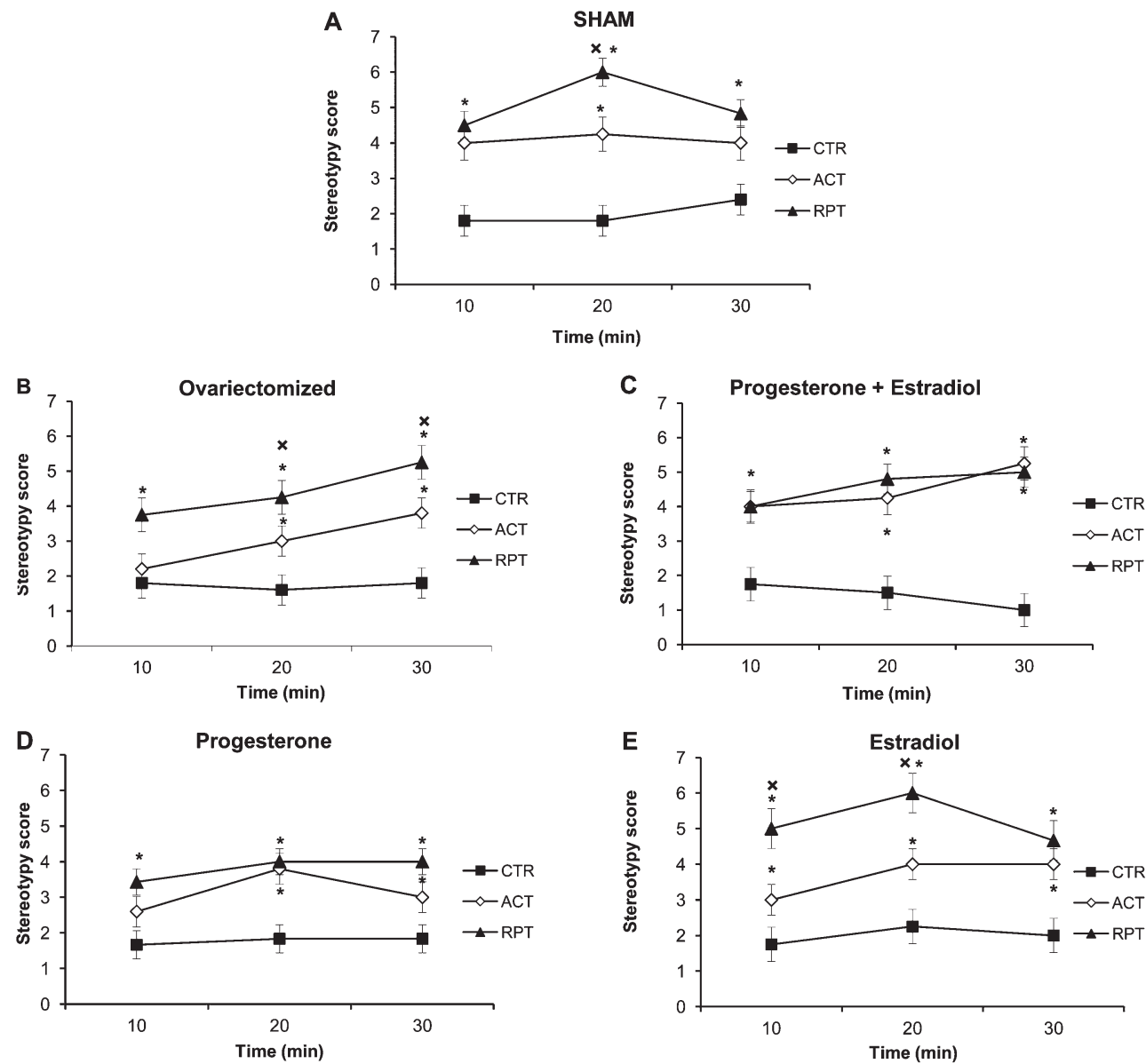

Figure 3. Stereotypic behaviors of female rats over the $30 \mathrm{~min}$ following administration of saline (CTR) or cocaine to acute (ACT) or repeated cocaine exposure (RPT) rats on the challenge treatment day, according to the different hormonal conditions. $A$, Sham-operated (SHAM) female rats. $B$, Ovariectomized female rats. $C$, Ovariectomized female rats treated with progesterone plus estradiol. $D$, Ovariectomized female rats treated with progesterone. $E$, Ovariectomized female rats treated with estradiol. Data are reported as means $\pm S E$. ${ }^{*} P<0.05$ compared to CTR; ${ }^{\mathrm{X}} \mathrm{P}<0.05$ compared to ACT (two-way repeated measures ANOVA followed by the Student-Newman-Keuls test).

even within an individual over time. Although most studies that assess behavioral sensitization to cocaine are performed in male animals, a handful of studies conducted in female rats have pointed to the presence of greater locomotor sensitization in females than males (13). Here, we showed that female rats exhibit higher locomotion and stereotypy scores in repeatedly cocaine-treated female rats than those only acutely treated with cocaine.
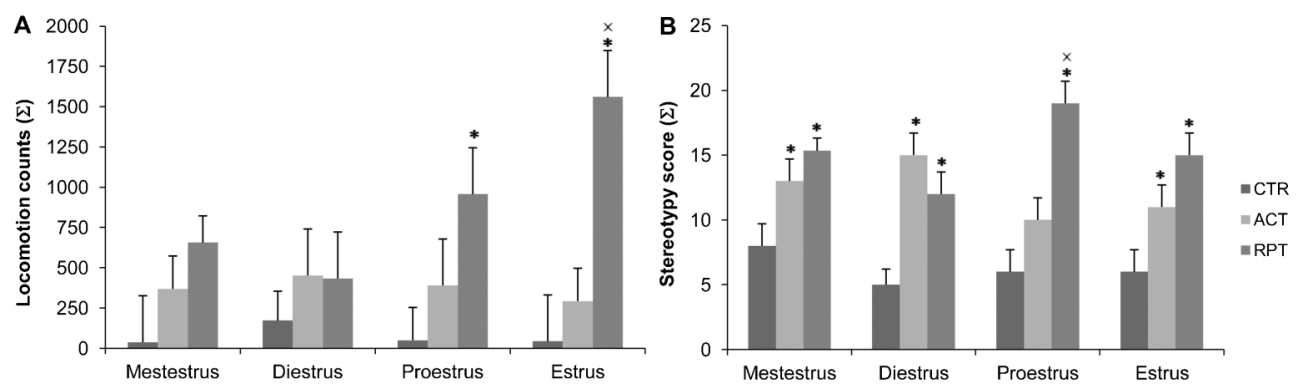

Figure 4. Behaviors of the sham-operated female rats according to estrous cycle phases and to cocaine treatment. $A$, Total locomotion counts. $B$, Sum of the stereotypy scores. Data are reported as means \pm SE. CTR: saline; ACT: acute cocaine; RPT: repeated cocaine. ${ }^{*} \mathrm{P}<0.05$ compared to CTR; ${ }^{\mathrm{P}}<0.05$ compared to ACT (two-way ANOVA followed by the Student-Newman-Keuls test). 

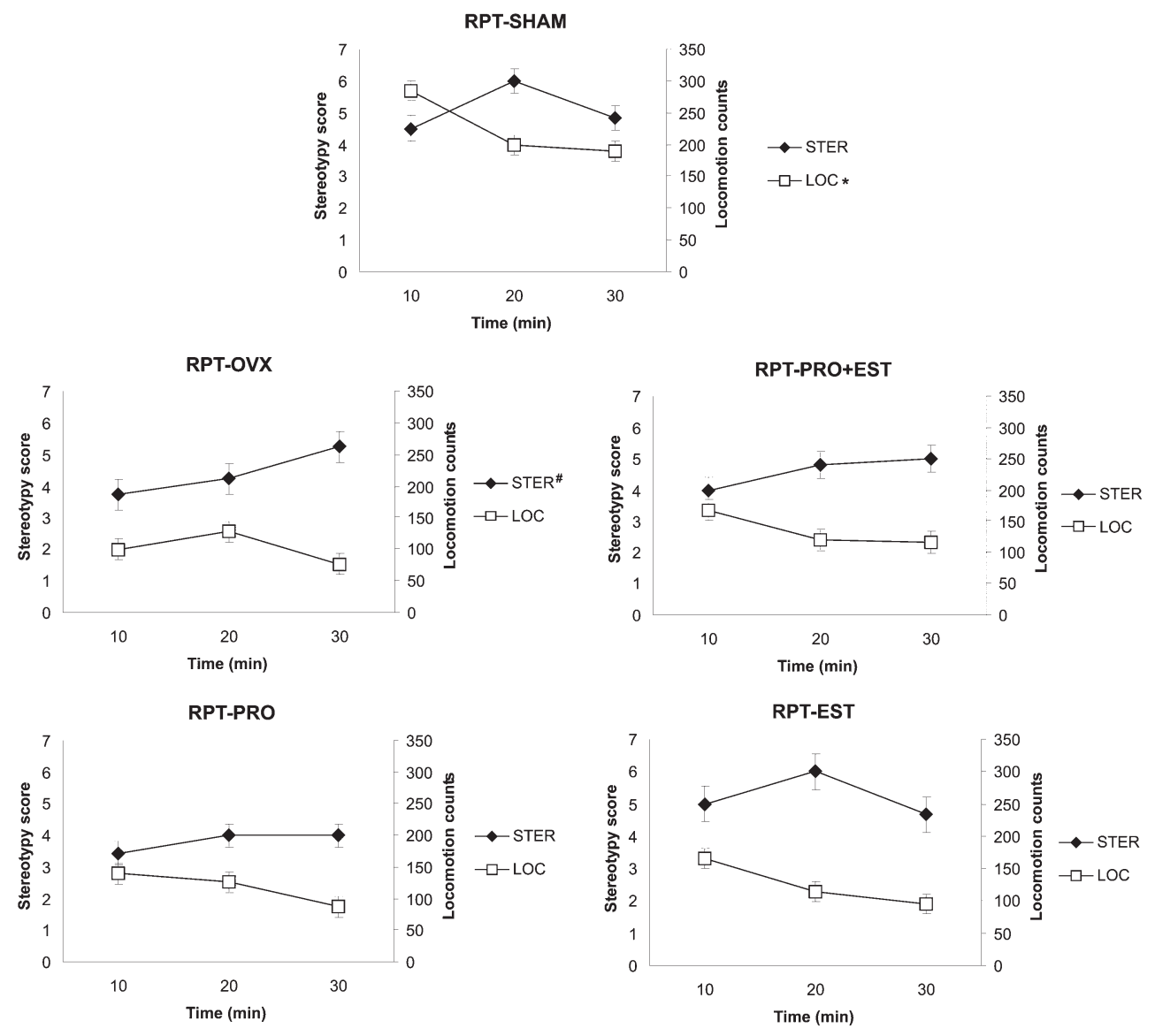

Figure 5. Correlation between locomotion counts or stereotypy scores and the time block (10, 20, or 30 min) after the challenge cocaine injection in female rats with repeated cocaine exposure. Data are reported as means \pm SE. STER: stereotypy score; LOC: locomotion counts; RPT: repeated cocaine; SHAM: sham-operated; OVX: ovariectomized; PRO + EST: progesterone + estradiol; PRO: progesterone; EST: estradiol. *Significant negative correlation; " significant positive correlation (Spearman test).

However, only sham-operated rats exhibited sensitization of both the locomotor and stereotypy behaviors. Chin et al. (9) also observed greater cocaine sensitization in hormonally intact female rats than in either ovariectomized female rats or male rats. These results also agree with others that point to the influence of hormonal fluctuations on the reinforcing properties of psychostimulant drugs in women (12).

Indeed, the psychostimulant effect after acute cocaine administration is greater during the proestrous and estrous phases in intact female rats, when estradiol is the main hormone and progesterone is still increasing in the plasma $(8,10,11)$. In the current study, we found that physiological hormones also exert an influence on behavioral sensitization after repeated cocaine administration in female rats. Cocaine sensitization was evident in the estrous and proestrous phases, which are described in the literature as the phases with increased levels of estradiol and progesterone (2). Furthermore, one-half of our sham-operated female rats were in the metestrous phase that, under our experimental conditions, corresponded to a high level of plasma estradiol. Coincidently, we also found that exogenous estradiol increased the locomotion and stereotypy behaviors in both the acute and repeated cocaine-treated rats. These results agree with previous studies showing that estradiol has an important role in cocaine sensitization in rats (14).

As expected, our OVX female rats did not show locomotor sensitization after a cocaine challenge. Previous studies have also found that ovariectomy decreases or delays behavioral sensitization to cocaine and also decreases self-administration behavior in female rats (12). However, although previous studies have not found a significant increase in stereotypy behavior after acute or repeated cocaine administration in OVX rats $(9,29)$, we found that acutely administered or cocaine-sensitized OVX rats had more stereotypy behaviors than control (salineinjected) rats. Curiously, exogenous progesterone, with or without estradiol, abolished these stereotypy behaviors in the OVX rats. 
The behavioral effects of exogenous estradiol and progesterone have been studied previously in cocainesensitized, ovariectomized female animals. Most studies found that estradiol administration is associated with increasing cocaine sensitization while progesterone administration is associated with a decrease of these behaviors (13). Here, we have found that endogenous estradiol increased locomotion (evidenced by higher estradiol levels in sham-operated rats, mainly in the estrous and proestrous phases). Rats in metestrous phase, that surprisingly showed elevated estradiol levels, did not present hyperlocomotion after cocaine. Moreover, estradiol replacement increased stereotypy behaviors in ovariectomized rats subjected to either acute or repeated treatments with cocaine. These results reproduced other findings that have shown an increased behavioral cocaine sensitization due to estrogen administration $(10,13,14)$. Therefore, it appears that estrogen plays an important role in the physiology of the cocaine reward process, increasing the sensitization mechanisms to cocaine in female rats. Indeed, it has been suggested that estradiol increases the psychostimulant effect of cocaine in rats through estrogen receptor alpha (30). Moreover, it causes changes in neuronal excitability that are regulated by gamma-aminobutyric acid type $B\left(G A B A_{B}\right)$ receptors on dopaminergic terminals in the striatum. Decreased activity of $\mathrm{GABA}_{B}$ receptors enhances dopamine release (2). The authors do not discount that other mechanisms such as the sensitization of catecholaminergic neurons by estradiol or estrogen's direct action on dopaminergic and serotonergic receptors may explain the modification of cocaine sensitization behaviors by estradiol $(3,6)$. We hypothesize that estradiol enhances the sensitization mechanisms and increases the magnitude of the locomotion and stereotypy behavior responses (31). Thus, we have shown that exogenous or endogenous estradiol increases the behavioral sensitization to cocaine in female rats.

Additionally, in our study, although OVX rats given progesterone or progesterone plus estradiol and then treated with cocaine showed greater stereotypy behavior when compared to controls, they exhibited a lack of the stereotypy behaviors characteristic of cocaine sensitization. These results agree with others who found that administration of progesterone alone resulted in a decrease of stereotypy behaviors in cocaine-sensitized female rats $(15,29)$. There is no consensus with respect to the coadministration of progesterone and estradiol. Some authors have found that progesterone plus estradiol increases locomotion but not stereotypy after repeated cocaine administration in OVX rats $(29,32)$. These discrepancies may be due to differences in dosage, because low doses of estradiol did not change locomotor activity in female rats that were given repeated cocaine treatments (15).
In addition to exogenous progesterone decreasing stereotypy behaviors, studies have shown other effects of progesterone relative to responses to cocaine, such as a) progesterone reverses the effects of estradiol on the acquisition of cocaine self-administration (16), b) progesterone attenuates motor responses to cocaine $(33,34)$, and $c$ ) progesterone inhibits place preference for cocaine in rats (35). Additionally, the hyperactivity induced by cocaine and cocaine self-administration is less during the estrous stages in which progesterone is higher $(10,16)$. In humans, although some studies show that progesterone is not effective in reducing cocaine use (20) and increases positive subjective effects of amphetamine (21), most show that progesterone attenuates the effects of cocaine in women (36).

The role of progesterone and its active metabolite, allopregnanolone, has been evaluated in the central nervous system (CNS) due to progesterone's positive modulation of GABA, the main inhibitory neurotransmitter in the CNS. In studies conducted in our laboratory, progesterone decreased the mRNA expression of GABA isoenzymes $\left(G A D_{65}\right.$ and $\left.G A D_{67}\right)$ in the prefrontal cortex of female rats (37). Additionally, the intrahippocampal administration of allopregnanolone enhanced the mRNA expression of the $\gamma_{2} \mathrm{GABA}_{\mathrm{A}}$ subunit (38). Both $\delta$ and $\gamma_{2}$ $\mathrm{GABA}_{\mathrm{A}}$ subunit expression increased in the rat hippocampus after allopregnanolone intranucleus accumbens treatment (39). Progesterone increased $\alpha_{1} \mathrm{GABA}_{\mathrm{A}}$ subunit mRNA in the prefrontal cortex of both male and female rats and decreased $\mathrm{GABA}_{\mathrm{A}} \gamma_{2}$ mRNA expression in male rats (40). Thus, we suggest that progesterone replacement attenuates the acute and chronic effects of cocaine in rats, possibly by the modulation of $\mathrm{GABA}_{\mathrm{A}}$ receptor subunits and GABA synthesis.

In this study, we have shown that endogenous or exogenous estradiol and progesterone differentially affect the behavioral responses of cocaine-sensitized female rats. Intact female rats showed sensitization of locomotor activity after a cocaine challenge, and progesterone decreased cocaine sensitization in ovariectomized rats. We infer from our data that the normal cyclic changes in both hormones increase the risk of drug abuse by potentiating cocaine sensitization mechanisms. The more important observation is that exogenous progesterone, given as a replacement in our study, decreases cocaine sensitization in female rats, and therefore may protect against drug dependence and drug use relapse. Future studies are needed to verify whether chronic progesterone administration is useful for the prevention and treatment of cocaine abuse, for both male and female individuals.

\section{Acknowledgments}

Research supported by UFCSPA, CNPq and CAPES. 


\section{References}

1. Steketee JD, Kalivas PW. Drug wanting: behavioral sensitization and relapse to drug-seeking behavior. Pharmacol Rev 2011; 63: 348-365, doi: 10.1124/pr.109.001933.

2. Lynch WJ, Roth ME, Carroll ME. Biological basis of sex differences in drug abuse: preclinical and clinical studies. Psychopharmacology 2002; 164: 121-137, doi: 10.1007/ s00213-002-1183-2.

3. Hu M, Becker JB. Acquisition of cocaine self-administration in ovariectomized female rats: effect of estradiol dose or chronic estradiol administration. Drug Alcohol Depend 2008; 94: 56-62, doi: 10.1016/j.drugalcdep.2007.10.005.

4. Walker QD, Cabassa J, Kaplan KA, Li ST, Haroon J, Spohr $H A$, et al. Sex differences in cocaine-stimulated motor behavior: disparate effects of gonadectomy. Neuropsychopharmacology 2001; 25: 118-130, doi: 10.1016/S0893133X(00)00248-7.

5. Becker JB, Hu M. Sex differences in drug abuse. Front Neuroendocrinol 2008; 29: 36-47, doi: 10.1016/j.yfrne.2007. 07.003 .

6. Segarra AC, Agosto-Rivera JL, Febo M, Lugo-Escobar N, Menendez-Delmestre R, Puig-Ramos A, et al. Estradiol: a key biological substrate mediating the response to cocaine in female rats. Horm Behav 2010; 58: 33-43, doi: 10.1016/ j.yhbeh.2009.12.003.

7. Sofuoglu M, Dudish-Poulsen S, Nelson D, Pentel PR, Hatsukami DK. Sex and menstrual cycle differences in the subjective effects from smoked cocaine in humans. Exp Clin Psychopharmacol 1999; 7: 274-283, doi: 10.1037/10641297.7.3.274.

8. Sell SL, Thomas ML, Cunningham KA. Influence of estrous cycle and estradiol on behavioral sensitization to cocaine in female rats. Drug Alcohol Depend 2002; 67: 281-290, doi: 10.1016/S0376-8716(02)00085-6.

9. Chin J, Sternin O, Wu HB, Burrell S, Lu D, Jenab S, et al. Endogenous gonadal hormones modulate behavioral and neurochemical responses to acute and chronic cocaine administration. Brain Res 2002; 945: 123-130, doi: 10.1016/ S0006-8993(02)02807-X.

10. Sell SL, Scalzitti JM, Thomas ML, Cunningham KA. Influence of ovarian hormones and estrous cycle on the behavioral response to cocaine in female rats. J Pharmacol Exp Ther 2000; 293: 879-886.

11. Quinones-Jenab V, Ho A, Schlussman SD, Franck J, Kreek MJ. Estrous cycle differences in cocaine-induced stereotypic and locomotor behaviors in Fischer rats. Behav Brain Res 1999; 101: 15-20, doi: 10.1016/S0166-4328(98)000734.

12. Quinones-Jenab V. Why are women from Venus and men from Mars when they abuse cocaine? Brain Res 2006; 1126: 200-203, doi: 10.1016/j.brainres.2006.08.109.

13. Festa ED, Quinones-Jenab V. Gonadal hormones provide the biological basis for sex differences in behavioral responses to cocaine. Horm Behav 2004; 46: 509-519, doi: 10.1016/j.yhbeh.2004.04.009.

14. Hu M, Crombag HS, Robinson TE, Becker JB. Biological basis of sex differences in the propensity to self-administer cocaine. Neuropsychopharmacology 2004; 29: 81-85, doi: 10.1038/sj.npp.1300301.

15. Yang $\mathrm{H}$, Zhao $\mathrm{W}, \mathrm{Hu} \mathrm{M}$, Becker JB. Interactions among ovarian hormones and time of testing on behavioral sensitization and cocaine self-administration. Behav Brain Res 2007; 184: 174-184, doi: 10.1016/j.bbr.2007.07.005.

16. Jackson LR, Robinson TE, Becker JB. Sex differences and hormonal influences on acquisition of cocaine self-administration in rats. Neuropsychopharmacology 2006; 31: 129138.

17. Larson EB, Roth ME, Anker JJ, Carroll ME. Effect of shortvs. long-term estrogen on reinstatement of cocaine-seeking behavior in female rats. Pharmacol Biochem Behav 2005; 82: 98-108, doi: 10.1016/j.pbb.2005.07.015.

18. Evans SM, Foltin RW. Does the response to cocaine differ as a function of sex or hormonal status in human and nonhuman primates? Horm Behav 2010; 58: 13-21, doi: 10.1016/j.yhbeh.2009.08.010.

19. Feltenstein MW, Byrd EA, Henderson AR, See RE. Attenuation of cocaine-seeking by progesterone treatment in female rats. Psychoneuroendocrinology 2009; 34: 343352, doi: 10.1016/j.psyneuen.2008.09.014.

20. Reed SC, Evans SM, Bedi G, Rubin E, Foltin RW. The effects of oral micronized progesterone on smoked cocaine self-administration in women. Horm Behav 2011; 59: 227235, doi: 10.1016/j.yhbeh.2010.12.009.

21. Reed SC, Levin FR, Evans SM. The effects of progesterone pretreatment on the response to oral d-amphetamine in Women. Horm Behav 2010; 58: 533-543, doi: 10.1016/ j.yhbeh.2010.04.003.

22. Scheggi S, Raone A, De Montis MG, Tagliamonte A, Gambarana C. Behavioral expression of cocaine sensitization in rats is accompanied by a distinct pattern of modifications in the PKA/DARPP-32 signaling pathway. J Neurochem 2007; 103: 1168-1183, doi: 10.1111/j.1471-4159.2007.04818.x.

23. Marcondes FK, Bianchi FJ, Tanno AP. Determination of the estrous cycle phases of rats: some helpful considerations. Braz J Biol 2002; 62: 609-614, doi: 10.1590/S151969842002000400008 .

24. Daunais JB, McGinty JF. Cocaine binges differentially alter striatal preprodynorphin and zif/268 mRNAs. Brain Res Mol Brain Res 1995; 29: 201-210, doi: 10.1016/0169328X(94)00246-B.

25. Creese I, Iversen SD. The role of forebrain dopamine systems in amphetamine induced stereotyped behavior in the rat. Psychopharmacologia 1974; 39: 345-357, doi: 10.1007/ BF00422974.

26. Montes GS, Luque EH. Effects of ovarian steroids on vaginal smears in the rat. Acta Anat 1988; 133: 192-199, doi: $10.1159 / 000146639$.

27. Flagel SB, Robinson TE. Quantifying the psychomotor activating effects of cocaine in the rat. Behav Pharmacol 2007; 18: 297-302, doi: 10.1097/FBP.0b013e3281f522a4.

28. Kuczenski R, Segal DS, Aizenstein ML. Amphetamine, cocaine, and fencamfamine: relationship between locomotor and stereotypy response profiles and caudate and accumbens dopamine dynamics. J Neurosci 1991; 11: 2703-2712.

29. Perrotti LI, Russo SJ, Fletcher H, Chin J, Webb T, Jenab S, et al. Ovarian hormones modulate cocaine-induced locomotor and stereotypic activity. Ann N Y Acad Sci 2001; 937: 202-216, doi: 10.1111/j.1749-6632.2001.tb03566.x.

30. Van Swearingen AE, Sanchez CL, Frisbee SM, Williams A, Walker QD, Korach KS, et al. Estradiol replacement 
enhances cocaine-stimulated locomotion in female C57BL/6 mice through estrogen receptor alpha. Neuropharmacology 2013; 72: 236-249, doi: 10.1016/j.neuropharm.2013.04.015.

31. Robinson TE, Becker JB. Enduring changes in brain and behavior produced by chronic amphetamine administration: a review and evaluation of animal models of amphetamine psychosis. Brain Res 1986; 396: 157-198, doi: 10.1016/ 0165-0173(86)90002-0.

32. Sircar R, Kim D. Female gonadal hormones differentially modulate cocaine-induced behavioral sensitization in Fischer, Lewis, and Sprague-Dawley rats. J Pharmacol Exp Ther 1999; 289: 54-65.

33. Russo SJ, Festa ED, Fabian SJ, Gazi FM, Kraish M, Jenab $S$, et al. Gonadal hormones differentially modulate cocaineinduced conditioned place preference in male and female rats. Neuroscience 2003; 120: 523-533, doi: 10.1016/S03064522(03)00317-8.

34. Russo SJ, Jenab S, Fabian SJ, Festa ED, Kemen LM, Quinones-Jenab V. Sex differences in the conditioned rewarding effects of cocaine. Brain Res 2003; 970: 214220, doi: 10.1016/S0006-8993(03)02346-1.

35. Niyomchai T, Russo SJ, Festa ED, Akhavan A, Jenab S, Quinones-Jenab V. Progesterone inhibits behavioral responses and estrogen increases corticosterone levels after acute cocaine administration. Pharmacol Biochem Behav 2005; 80: 603-610, doi: 10.1016/j.pbb.2005.01.010.
36. Evans SM. The role of estradiol and progesterone in modulating the subjective effects of stimulants in humans. Exp Clin Psychopharmacol 2007; 15: 418-426, doi: 10.1037/ 1064-1297.15.5.418.

37. Souza MF, Toniazo VM, Frazzon AP, Barros HM. Influence of progesterone on GAD65 and GAD67 mRNA expression in the dorsolateral striatum and prefrontal cortex of female rats repeatedly treated with cocaine. Braz J Med Biol Res 2009 42: 1068-1075, doi: 10.1590/S0100-879X2009001100011.

38. Nin MS, Salles FB, Azeredo LA, Frazon AP, Gomez R, Barros HM. Antidepressant effect and changes of GABAA receptor gamma2 subunit mRNA after hippocampal administration of allopregnanolone in rats. J Psychopharmacol 2008; 22: 477-485, doi: 10.1177/0269881107081525.

39. Nin MS, Ferri MK, Couto-Pereira NS, Souza MF, Azeredo LA, Agnes G, et al. The effect of intra-nucleus accumbens administration of allopregnanolone on delta and gamma2 $\mathrm{GABA}(\mathrm{A})$ receptor subunit mRNA expression in the hippocampus and on depressive-like and grooming behaviors in rats. Pharmacol Biochem Behav 2012; 103: 359-366, doi: 10.1016/j.pbb.2012.09.002.

40. Andrade S, Arbo BD, Batista BA, Neves AM, Branchini G, Brum IS, et al. Effect of progesterone on the expression of $\operatorname{GABA}(A)$ receptor subunits in the prefrontal cortex of rats: implications of sex differences and brain hemisphere. Cell Biochem Funct 2012; 30: 696-700, doi: 10.1002/cbf.2854. 